\title{
The Importance of Control Monitoring Systems in Wind Parks Maintenance
}

\author{
R. F. Mesquita Brandão ${ }^{1^{*}}$ and J. A. Beleza Carvalho ${ }^{1}$ \\ ${ }^{1}$ ISEP-School of Engineering, Polytechnic of Porto, Porto, Portugal.
}

Authors' contributions

This work was carried out in collaboration between all authors. Author RFMB developed the study and wrote the draft of the manuscript. Author JABC performed the analyses of the study and literature searches. All authors read and approved the final manuscript.

Original Research Article

Received $7^{\text {th }}$ November 2013

Accepted $13^{\text {th }}$ December 2013

Published $5^{\text {th }}$ February 2014

\section{ABSTRACT}

The objective of every wind energy producer is to reduce operational costs associated to the production as a way to increase profits. One other issue that must be looked carefully is the equipment maintenance. Increase the availability of wind turbines by reducing the downtime associated to failures is a good strategy to achieve the main goal of increase profits.

As a way to help in the definition of the best maintenance strategies, condition monitoring systems (CMS) have an important role to play. Informatics tools to make the condition monitoring of the wind turbines were developed and are now being installed as a way to help producers reducing the operational costs. There are a lot of developed systems to do the monitoring of a wind turbine or the whole wind park, in this paper will be made an overview of the most important systems.

Keywords: CMS; Failures; Maintenance; Wind turbine.

\section{INTRODUCTION}

Wind turbines are very developed systems and are composed by a very large number of components. The failure rate of wind turbines tends to reduce during the system useful life, but is necessary to have good monitoring systems to avoid large operational and maintenance costs. 
One other issue that is important to understand is the failure rate evolution. The "bath curve" is also applied to wind turbines. Fig. 1 presents the typical failure rate evolution associated to equipment's.

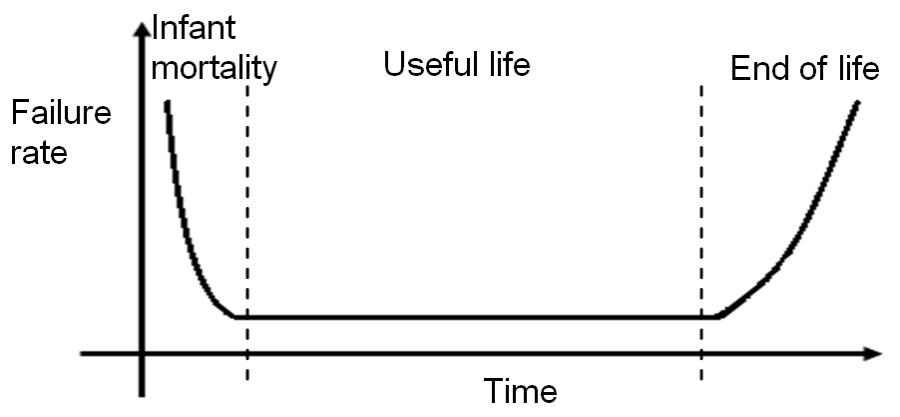

Fig. 1. Time fault evolution [1]

Failure rate is higher in the beginning, normally because of problems with the installation and adjustments. Then, during the useful life, failure rate is low and in the end of life failure rate increase again. This is an important issue because older wind parks are no longer under warranty contracts and for that reason maintenance operations are contracted to the job, which implies a cost to the wind park owner.

The general availability of wind turbines is increased by maximizing the time between failures and overhaul, planning in advance the most appropriate maintenance intervals, the logistics, the need for spare parts and working hours needed to the job. One of the factors that influence the planning of maintenance actions is the weather. If weather conditions do not allow access to the turbines, maintenance is not done. On the other hand if there are ideal conditions for the production of energy, hardly the owner of the park authorize the shutdown of machines, and the consequent loss of economic returns. For all these reasons is necessary to develop monitoring systems that can give good and real "images" of the system under monitoring and with the possibility of make some forecast of future failures in some important equipment.

The monitoring tools can be more needed in systems were the access is not easy, like offshore wind parks. Presently are installed and connected to the grid, in Europe, 1662 wind turbines in 55 offshore wind farms, totalizing an amount of power of almost $5 \mathrm{GW}$ [2]. In 2020, European Wind Energy Association target for offshore installations is $40 \mathrm{GW}$. Due to the expected evolution in this sector, wind turbines monitoring systems are expected to assume a more important role in the exploitation of wind energy and in the definition of new maintenance strategies.

\section{WIND TURBINES MAINTENANCE}

In order to have a good understanding of the problems of maintenance management is necessary to understand the time periods associated with the functioning and stopping of equipment. It is also necessary to understand the concept of reliability and maintainability of a system.

These concepts, although very similar, does not mean the same thing. According to [3], reliability is the ability of a system or component to perform its functions under certain 
conditions and for a certain period of time. Maintainability is the ability from one installation to be maintained or restored in availability status, being the maintenance carried out under appropriate conditions, with the procedures and means foreseen [4].

There are some indicators that can be used to evaluate the performance of the systems, taking into account the number and duration of interruptions. The mean time to failure (MTBF) and mean time to repair (MTTR) are two of them.

The MTBF, which may be calculated by (1), is an indication parameter of the quality of the system.

$$
M T B F=\frac{\sum_{i=0}^{n} T B F_{i}}{n}
$$

Where TBFi, represents the functioning time without failures and $\mathrm{n}$ represents the number of failures in a given period.

MTTR is the average time to repair the system when a failure is present and include the time taken to diagnose the problem, how long the repair team takes to arrive to the local and the time taken to physically repair the system. This indicator can be calculated by (2).

$$
\operatorname{MTTR}=\frac{\sum_{i=0}^{n} T T R_{i}}{n}
$$

Where TTRi represents the time to repair and $\mathrm{n}$ represents the number of failures in a given period.

Wind farms maintenance is classified into two types, the corrective and the preventive maintenance. The corrective maintenance is performed after the occurrence of a fault and the objective is to repair the systems and put it on running. Interventions to improve the overall equipment can be made even without failure.

Preventive maintenance is performed at predetermined periods of time or according certain criteria. The main objective is to reduce the probability of occurrence of an anomaly. The preventive maintenance can be divided into two sub types, the systematic or planned maintenance and condition based maintenance, differing only by the method of deciding when to perform maintenance. Fig. 2 presents the diagram of maintenance classification.

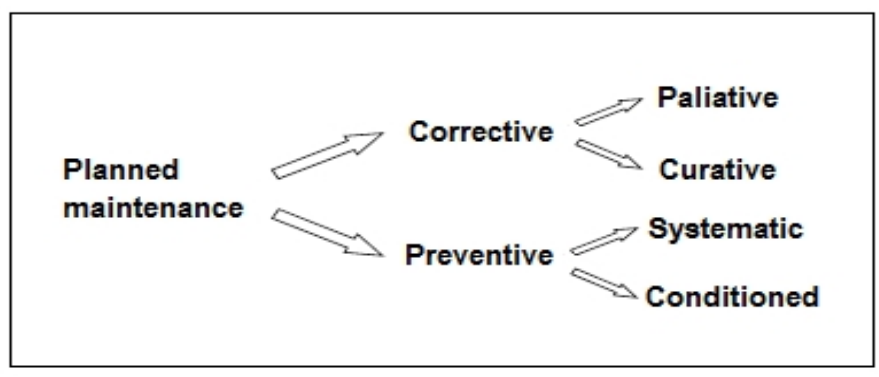

Fig. 2. Maintenance classification [6]

In the first installed wind turbines maintenance practices were essentially corrective, with the main objective of keeping systems in operation until the fail. However, as the wind turbines 
increased capacity, preventive maintenance was becoming increasingly adopted and many operators are now employing periodic inspections to evaluate the state of the systems based on empirical and subjective measures [5].

Nowadays, most of wind turbine producers impose a maintenance strategy based on time in which maintenance teams go regularly to the turbine to make inspections, repairs and substitution of equipment's. Normally two maintenances are made per year. This systematic maintenance is based in pre-defined tasks in were maintenance teams know exactly what to do. Due to safety restrictions the maintenance can only be performed under specific weather conditions.

Enercon, one of the biggest wind turbines producers, has a different maintenance strategy. Every 3 months is made an inspection to the turbine, but inspections are specific to predetermined sectors of machine. Fig. 3 shows the strategy and the sectors analyzed in each inspection.

While the first maintenance plan needs multidisciplinary maintenance teams, the maintenance plan imposed by Enercon, uses specialized maintenance personnel for each inspection.

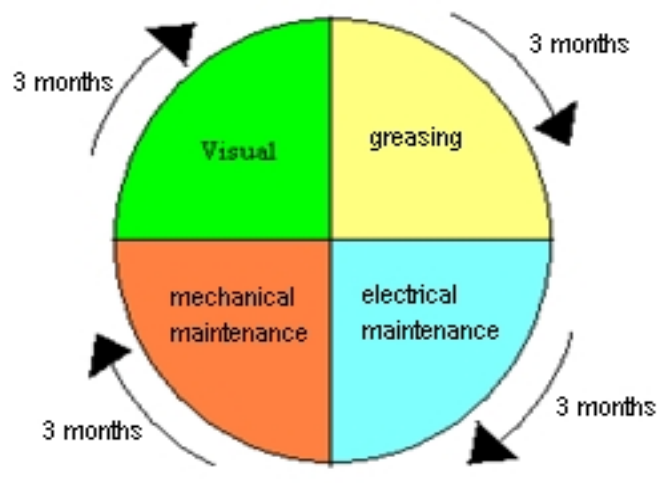

Fig. 3. Enercon maintenance planning [7]

Maintenance strategy based on time, has some handicaps. If time interval between maintenances is to short, operational costs increases and wind turbine outage time increases too, due to the necessity of stop the machine to do the work. On the other hand, more unexpected faults occur when time interval between inspections is long.

To solve this paradigm some producers and wind park owners started to develop maintenance strategies based on equipment condition monitoring. Using these techniques is possible to optimize the maintenance as a way of increase the availability and reduce operational costs.

Several studies were made about this issue, comparing the advantages and disadvantages of maintenance strategies. Fig. 4 shows the comparison between three of the most common strategies. 


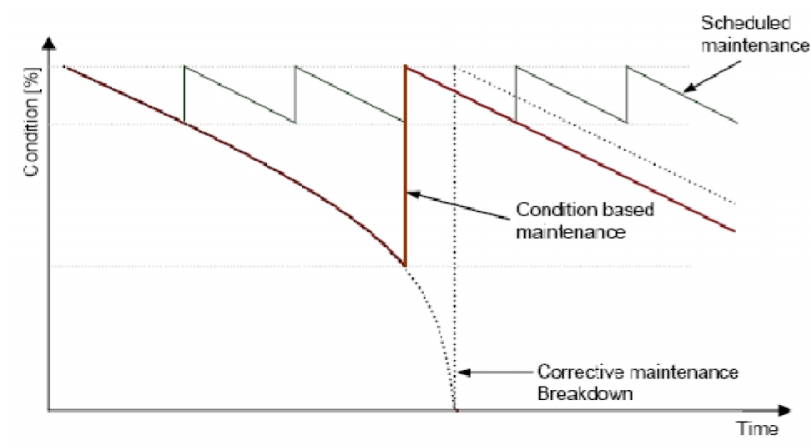

Fig. 4. Maintenance strategies comparison [8]

Table 1 show some advantages and disadvantages for the different maintenance methods when applied to wind turbines.

As is possible to see in Table 1, condition based maintenance is a very developed method and is, nowadays, included in the most developed condition monitoring systems.

Any maintenance strategy can include the three types of methods defined in Table 1. In that case it will be a combination of corrective and preventive maintenance, but the main objective is always the same, increase the operation time of the system and reducing the operational costs.

Table 1. Comparison of maintenance methods [8]

\begin{tabular}{|c|c|c|}
\hline Method & Advantages & Disadvantages \\
\hline $\begin{array}{l}\text { Corrective } \\
\text { maintenance }\end{array}$ & $\begin{array}{l}\text { Low maintenance costs } \\
\text { during operation. } \\
\text { Components will be used for } \\
\text { a maximum lifetime. }\end{array}$ & $\begin{array}{l}\text { High risk in consequential damages } \\
\text { resulting in extensive downtimes. } \\
\text { No maintenance scheduling is } \\
\text { possible. } \\
\text { Spare parts logistics is complicated } \\
\text { Long delivery periods for parts are } \\
\text { likely }\end{array}$ \\
\hline $\begin{array}{l}\text { Preventive } \\
\text { Maintenance } \\
\text { Scheduled }\end{array}$ & $\begin{array}{l}\text { Expected downtime is low. } \\
\text { Maintenance can be } \\
\text { scheduled. } \\
\text { Spare logistics is easy }\end{array}$ & $\begin{array}{l}\text { Components will not be used for } \\
\text { maximum lifetime. } \\
\text { Maintenance costs are higher } \\
\text { compared to corrective } \\
\text { maintenance. }\end{array}$ \\
\hline $\begin{array}{l}\text { Preventive } \\
\text { Maintenance } \\
\text { Condition based }\end{array}$ & $\begin{array}{l}\text { Components will be used up } \\
\text { to almost their full times. } \\
\text { Expected downtime is low. } \\
\text { Maintenance activities can } \\
\text { be scheduled. } \\
\text { Spare part logistics is easy } \\
\text { given that a failure can be } \\
\text { detected early in time. }\end{array}$ & $\begin{array}{l}\text { Reliable information about the } \\
\text { remaining lifetime of the components } \\
\text { is required. } \\
\text { High effort for condition monitoring } \\
\text { hardware and software is required. } \\
\text { Cost of another layer in the system. } \\
\text { Not a mature market for monitoring } \\
\text { systems within wind power. } \\
\text { Identification of appropriate condition } \\
\text { threshold-values is difficult. }\end{array}$ \\
\hline
\end{tabular}




\section{CONDITION MONITORING SYSTEMS}

The objective of condition monitoring systems (CMS) is to allow for condition-based maintenance. Most of the times this service is contracted to third party companies, but some constructors provide this service too.

The key advantage of a CMS is the permanent automatic monitoring and evaluation of trends under comparable operating conditions.

This service is quite obligatory in offshore installations and is used in the most technological wind turbines onshore clients.

Due to the fast development of wind turbines industry, with the inherent increase of occurrences of damages and as a result of the large investments required for multi-MW and offshore turbines and the necessity for cost-optimized maintenance, operators and insurance companies increasingly demanded a condition-based monitoring of wind turbines.

Currently CMS are generally based on vibration monitoring technology of the drive train of wind turbines. The restricted accessibility of offshore plants constitutes an important reason for expanding the condition monitoring to structural components of the wind energy converter and to refine the monitoring of the drive train with supplementary methods $[9,10]$.

Condition monitoring requirements for wind turbines are unique. The system must be low cost and give early and reliable fault detection, accurate fault diagnosis and the ability to handle input from several thousand transducers in a system where no faults must be missed and no false alarms are acceptable.

There are a lot of companies that provide CMS tools strictly dedicated to wind turbines, but all systems must monitor some equipment as minimum requirements, imposed by the Guideline for the certification of Condition Monitoring Systems for Wind Turbines [11].

Table 2 and Fig. 5 show the minimum sensors needed and the equipment that need to be under monitoring in a CMS.

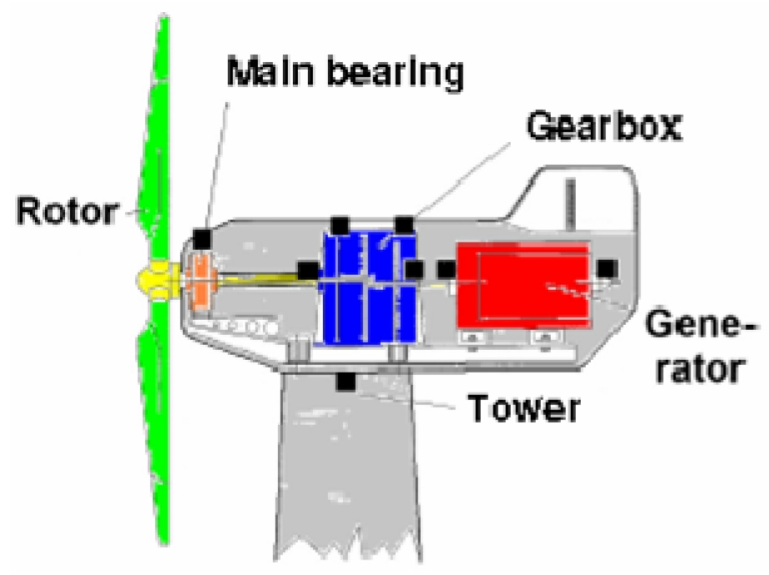

Fig. 5. Wind turbine drive train points to be monitored [11] 
Table 2. Minimum number of sensors [11]

\begin{tabular}{ll}
\hline Wind turbine equipment & Number of sensors \\
\hline Main bearing & 1 per bearing \\
Gearbox & 3 or more \\
Generator & 1 per bearing \\
Tower & 2 \\
\hline
\end{tabular}

All information obtained by the CMS must be analysed and some items have to be considered during the analysis, like the establishment of correlation between measured vibration and operating data and is necessary to compare data with threshold values that must be well defined to avoid error alarm messages.

The way that storage data is used and the procedures when threshold values are exceeded are defined and regulated.

\section{CMS CASE STUDIES}

Most of major wind turbines producers use CMS offered by specific companies existent in market, like the SKF, BKV, Bachman and others.Producers like Enercon, Nordex and Siemens have their own products. The most important characteristics of those products will be presented next.

SKF: Is the CMS used by Repower wind turbines as an optional product. The main objective is to monitor the drive train using information, like operating data, oil analyses and visual inspection and vibration. Combination of all this data sources is possible to prevent unexpected downtime, reduce planned downtime and limit the possible extend of the damage identified. 8 vibration sensors are placed in the drive train at appropriated points. Fig. 6 shows a possible placement of sensors. Small yellow circles in Fig. 6 represent the sensors location. One sensor is placed in the main bearing, 5 sensors are located in the gearbox (2 in the planetary stage and other 3 in the output shaft), the last 2 sensors are placed in the generator bearing. Then, wind turbine SCADA will collect and store data which is transmitted to a CMS server for manual analysis by diagnosis experts downstream [12].

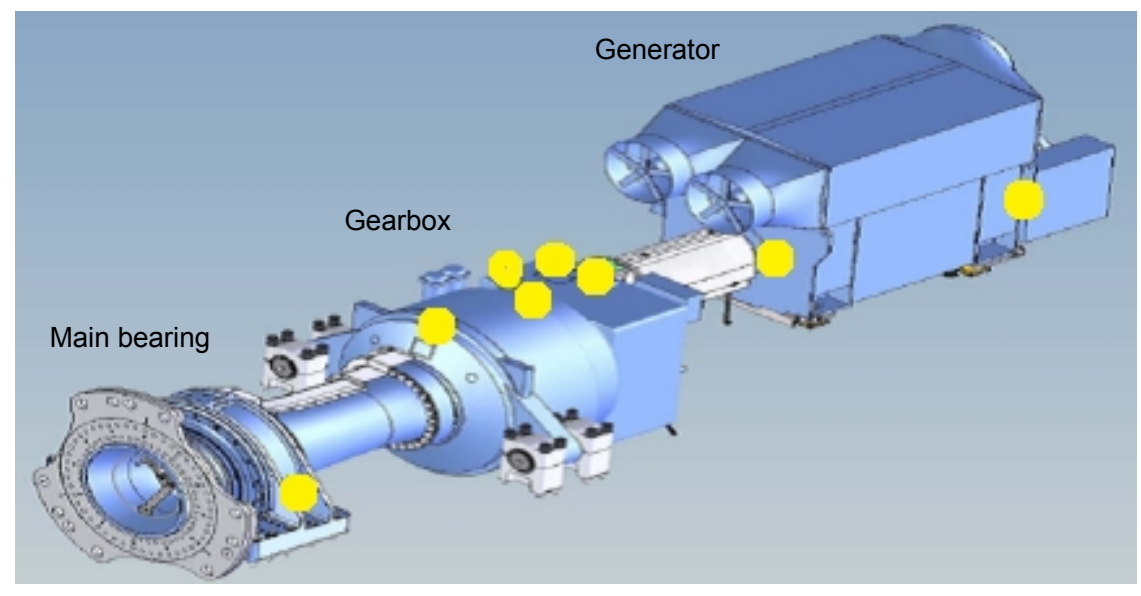

Fig. 6. Position of accelerometers on the drive train [12] 
In case of irregularities on the wind turbine, the CMS data is compared with the data from other sources of information and necessary action is taken using a predefined action plan.

BKV: Is a remote condition monitoring program for wind turbines developed by Brüel\&Kjaer Vibro and used by Vestas. The system includes local data acquisition units; alarm management and review of all alarms by specialized personnel; reporting actionable information to customer service groups.

BKV CMS: Is design to monitor 5 systems. Bearings, coupling, shaft, gearbox and support structure, with the objective of diagnose and detect faults in early stage. Measurements made in these systems associated with operating condition measurements and vibrations are analysed in the BKV condition monitoring centre and status reports are made and validated in the Customer Service \& Control Centre where information is passed to customer together with a diagnostic evaluation of the alarms [13].

BACHMANN CMS: Is the CMS developed by Bachmann electronic GmbH and is a PLCintegrated condition monitoring solution that uses the power supply and communication network of the PLC. In terms of sensors, system uses 6 vibration sensors in order to monitor main bearings, main gears and generator. In addition are installed acceleration sensors in the nacelle and tower. Fig. 7 shows the equipment under monitoring.

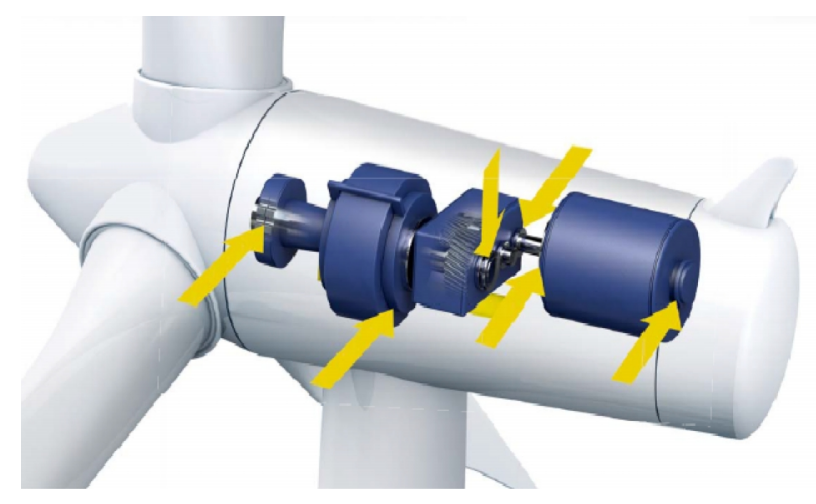

Fig. 7. Equipment under monitoring [14]

Information collected is managed in the WebLog server and in case of any fault occurring it is automatically logged by the system and an appropriated report is sent to the workstation. The Bachmann online CMS provides worldwide access to the status data of the monitored plant from any online workstation enabling the operator to watch all wind power plants.

ENERCON CMS: The Enercon CMS is developed by Enercon and is based in the SCADA of the wind turbines. Every turbine is connected with the central remote data monitoring facility and in the presence of a fault the service centre and the service branch in charge are notified via the SCADA remote monitoring system. The deployment planning system automatically locates the service team that is closest to the wind turbine with problem.

Maintenance technicians have laptops with access to all turbines documents, ensuring that all faults are dealt with as quickly and efficiently as possible [15]. 
NORDEX CMS: Nordex has its own CMS that can be installed in all new wind turbines as well as those already installed. The system monitors and saves data, using special acceleration sensors attached to the main bearing, gearbox and generator, which continuously measure the vibration pattern of components.

The system automatically draws up a comparison between the ideal and real turbine situation and if a discrepancy exists or if limits are exceeded, the system sends a warning or alarm message to the central Nordex remote monitoring system, where actions to be done are decided, based on the degree of change or wear and on the basis of experience.

SIEMENS CMS: Siemens offers 2 condition monitoring systems, depending on requirements. One, simpler, supports detailed damage detection using 16 vibration sensors. All data can be recorded and exported. The other CMS is more powerful because it can acquire and analyse up to 180 vibration signals in parallel and synchronously. Operating turbine data can be integrated in the CMS, which enables an overall analysis of the turbines condition.

Sensors are placed in the drive train with the objective of monitoring the bearing, gearbox and generator. Fig. 8 shows the elements under monitoring.

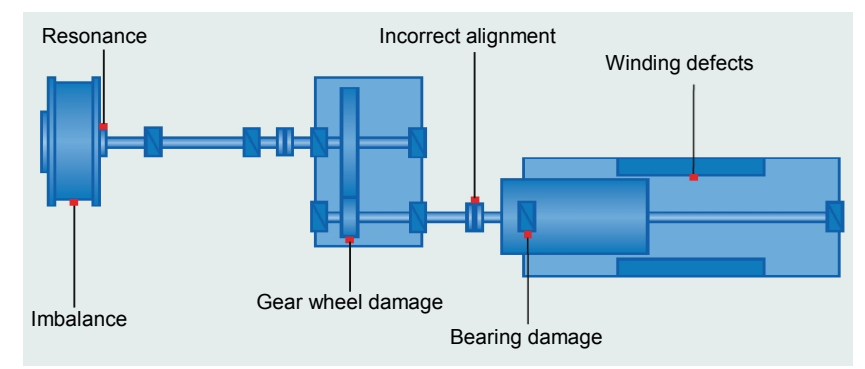

Fig. 8. Diagnostics for a drive train using vibration analysis [16]

All sensors are connected to the condition monitoring systems equipment which is connected to the Automation \& Turbine Control of the nacelle by PROFINET. Fig. 9 presents the communication and data flow. The black line represents the connection of the sensors to the condition monitoring system. Green and yellow line represents the PROFINET/PROFI safe system and the green line represents the PROFINET system.

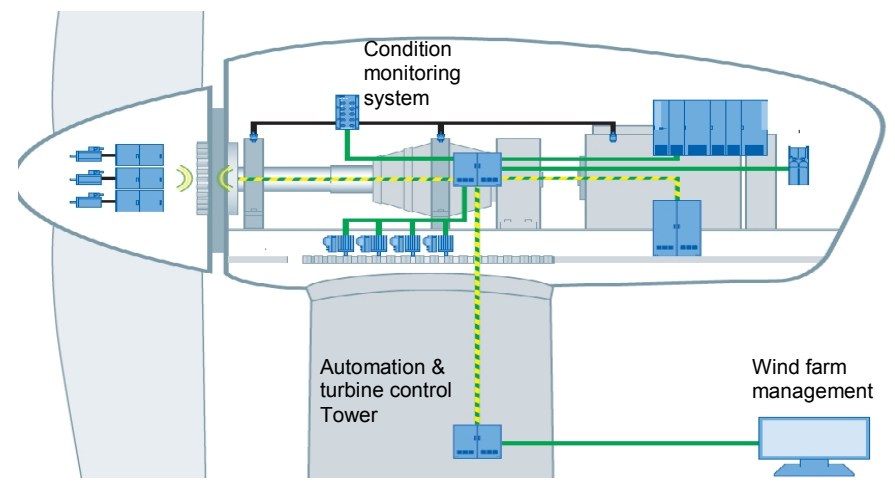

Fig. 9. Communication and data flow [17] 


\section{CONCLUSION}

This paper presents some available CMS in use by the wind turbines producers.

The advantages of use CMS are very clear but is possible to highlight: the increase in turbine availability and optimization of the service life of the equipment units within the wind turbine; the possibility of implementation of intelligent, scheduled maintenance concepts; the achieve of maximum productivity and protection, through permanent monitoring of important processes of the wind turbine; and the major objective that is possible to achieve is the reduced maintenance costs.

Condition monitoring provides reliable information about the state of important mechanical and electrical components of the wind turbine. This enables any faults to be detected early as well as preventing any possible consequential damage that would mean a lengthy downtime of the installation.

The possibility of have a real picture of the condition of the plant and of the expected risk of loss, offered by a CMS, are important issues, particularly in the end of warranty periods when is necessary to recalculate insurance contracts.

\section{COMPETING INTERESTS}

Authors have declared that no competing interests exist.

\section{REFERENCES}

1. Jesse A. Andrawus, John Watson, Mohammed Kishk. Wind Turbine Maintenance Optimisation: principles of quantitative maintenance optimization. Wind Engineering Journal. 2007;31(2):101-110.

2. European Wind Energy Association EWEA. The European offshore wind industry-key trends and statistics 2012, 2012 Report. January 2013.

3. Institute of Electrical and Electronics Engineers. IEEE 90: IEEE Standard Glossary of Software Engineering Terminology; 1990.

4. DGGE/CERTIEL. RTIEBT- Portuguese Regulation for Electrical Installations; 2006.

5. Hyers RW, McGowan JG, Sullivan KL, Manwell JF, Syrett BC. Condition monitoring and prognosis of utility scale wind turbines," Energy Materials: Materials Science and Engineering for Energy Systems. 2006;1:187-203.

6. N. EN. "NP EN 13306:2007 - Maintenance Terminology", ed, 2007.

7. E. S. D. GmbH, Maintenance Instructions, Enercon, March 2007.

8. Ribrant J. Reliability performance and maintenance - A survey of failures in wind power systems", Master Thesis, KTH School of Electrical Engineering, Stockholm. 2005-2006.

9. Gellerman T. Extension of the scope of Condition Monitoring Systems for multi-MW and offshore wind turbines. Abstract of Conference Proceedings from VDIConference, Schwingungen von Windenergieanlagen 2012, 7-8 February, Bremen, Germany, 2012.

10. Steingröver K, Hermann J, van Bonn D. Condition Monitoring Systems for Wind Turbines: Present Status and Future Developments, a Certification's View, Germanisher Lloyd Industrial Services, Renewables Certification. 
11. Germanischer Lloyd. Guideline for the Certification of Condition Monitoring Systems for Wind Turbines; 2003.

12. Repower Systems SE. Vibration-based Drive Train Condition Monitoring System. Document no. PD-2.5-WT.SE.00-A-A-EN, 2011.

13. Brüel\&Kjaer Vibro. We deliver lead-time to maintenance - Remote Condition Monitoring Program for Wind Turbines, Lit. no. BBR 0030-EN-11.

14. Bachmann. CMS- Condition Monitoring Systems. Condition Monitoring Brochure EN PB-CMS/02EN, May 2012.

15. Enercon. ENERCON Technololy\& Service - Making wind your Future, ENERCON magazine, March 2011.

16. SIEMENS. Efficient Maintenance-Applications with Totally Integrated Automation. Brochure, November 2011.

17. SIEMENS. Creating the most from wind - due to perfectly coordinated products ans systems. Brochure, March 2013.

(c) 2014 Brandão and Carvalho; This is an Open Access article distributed under the terms of the Creative Commons Attribution License (http://creativecommons.org/licenses/by/3.0), which permits unrestricted use, distribution, and reproduction in any medium, provided the original work is properly cited.

Peer-review history:

The peer review history for this paper can be accessed here:

http://www.sciencedomain.org/review-history.php?iid=423\&id=5\&aid=3551 